\title{
Effects of Thyroid Hormone Treatment on Diaphragmatic Efficiency in Mechanically Ventilated Subjects With Nonthyroidal Illness Syndrome
}

\author{
Giuseppe Bello, Giorgia Spinazzola, Valentina Giammatteo, Luca Montini, Gennaro De Pascale, \\ Alessandra Bisanti, Maria G Annetta, Eliana Troiani, Antonio Bianchi, Alfredo Pontecorvi, \\ Mariano A Pennisi, Giorgio Conti, and Massimo Antonelli
}

BACKGROUND: Several respiratory abnormalities can be present in primary hypothyroidism and can be reversed with adequate hormone treatment. However, the role of thyroid hormone replacement therapy on the respiratory system in patients with nonthyroidal illness syndrome is still unclear. This physiologic study evaluated the effect of thyroid hormone treatment on respiratory muscle function in subjects with nonthyroidal illness syndrome and while on mechanical ventilation. The primary end point was neuromechanical efficiency, which provides an estimate of the efficiency of diaphragmatic contraction. Secondary end points were the transdiaphragmatic pressure-time product and the swing of the electrical activity of the diaphragm, which reflect the work of breathing and inspiratory effort, respectively. METHODS: Fifteen subjects on mechanical ventilation for $\geq 48 \mathrm{~h}$ and with a diagnosis of nonthyroidal illness syndrome who had a failed spontaneous breathing trial, received intravenous triiodothyronine. The hormone was administered as an intravenous bolus of $0.4 \mu \mathrm{g} / \mathrm{kg}$ triiodothyronine, followed by continuous perfusion at $0.6 \mu \mathrm{g} / \mathrm{kg}$ for $24 \mathrm{~h}$. Neuromechanical efficiency was calculated as the ratio between the drop in airway pressure during an expiratory occlusion and the corresponding electrical activity of the diaphragm peak. Recordings were taken at baseline and after 3, 6, and $24 \mathrm{~h}$. RESULTS: After study completion, free triiodothyronine serum concentrations increased in all the subjects (mean \pm SD increase, $0.84 \pm 0.34 \mathrm{pg} / \mathrm{mL}$ ). Neuromechanical efficiency showed no significant changes throughout the study (mean \pm SD baseline, $1.40 \pm 0.87 \mathrm{~cm} \mathrm{H}_{2} \mathrm{O} / \mu \mathrm{V} ; 3 \mathrm{~h}, 1.28 \pm 0.64 \mathrm{~cm}$ $\left.\mathrm{H}_{2} \mathrm{O} / \mu \mathrm{V} ; 6 \mathrm{~h}, 1.33 \pm 0.87 \mathrm{~cm} \mathrm{H2O} / \mu \mathrm{V} ; 24 \mathrm{~h}, 1.41 \pm 0.96 \mathrm{~cm} \mathrm{H}_{2} \mathrm{O} / \mu \mathrm{V}\right)$. Similarly, no variations in transdiaphragmatic pressure-time product per min (mean $\pm \mathrm{SD}$ baseline, $238.1 \pm 124 \mathrm{~cm} \mathrm{H}_{2} \mathrm{O} \times \mathrm{s} / \mathrm{min}$; $3 \mathrm{~h}, 242.5 \pm 140.3 \mathrm{~cm} \mathrm{H} \mathrm{H}_{2} \mathrm{O} \times \mathrm{s} / \mathrm{min} ; 6 \mathrm{~h}, 247.5 \pm 161.7 \mathrm{~cm} \mathrm{H} \mathrm{H}_{2} \mathrm{O} \times \mathrm{s} / \mathrm{min} ; 24 \mathrm{~h}, 281.2 \pm 201.2 \mathrm{~cm} \mathrm{H}_{2} \mathrm{O} \times$ $\mathrm{s} / \mathrm{min}$ ) or swing of electrical activity of the diaphragm (mean \pm baseline, $20.9 \pm 13.1 \mu \mathrm{V} ; 3 \mathrm{~h}, 17.2 \pm 8.3$ $\mu \mathrm{V} ; 6 \mathrm{~h}, 17.4 \pm 11.3 \mu \mathrm{V} ; 24 \mathrm{~h}, 20.3 \pm 13.7 \mu \mathrm{V}$ ) were observed during hormone administration. CONCLUSIONS: In the subjects on mechanical ventilation who were admitted to the ICU with nonthyroidal illness syndrome, thyroid hormone replacement treatment did not yield any benefit on respiratory muscle function when assessed by neuromechanical efficiency, which indicated that, in these subjects restoring normal levels of serum thyroid hormones is debatable. (ClinicalTrials.gov registration NCT03157466.) Key words: respiratory failure; mechanical ventilation; intensive care unit; thyroid hormones; diaphragm; respiratory muscle. [Respir Care 2019;64(10):1199-1207. (c) 2019 Daedalus Enterprises]

\section{Introduction}

The nonthyroidal illness syndrome refers to changes in serum thyroid hormone levels observed in patients who

Drs Bello, Spinazzola, Giammatteo, Montini, De Pascale, Bisanti, Annetta, Pennisi, Conti, and Antonelli are affiliated with Dipartimento di Scienze dell'Emergenza, Anestesiologiche e della Rianimazione; UOC di are critically ill and with no previously diagnosed intrinsic thyroid disease. ${ }^{1}$ The laboratory parameters of nonthyroidal illness syndrome include low serum levels of triiodothyronine and high levels of reverse triiodothyronine, with 
normal or low levels of thyroxine and normal or low levels of thyroid-stimulating hormone. It is still unclear whether nonthyroidal illness syndrome is a protective adaptation to

\section{See the Related Editorial on Page 1322}

illness or a maladaptive response to a stressful insult. Likewise, it remains unanswered whether laboratory abnormalities of nonthyroidal illness syndrome should be corrected.

Although it is now recognized that a variety of respiratory abnormalities, for example, diaphragmatic dysfunction, can be present in primary hypothyroidism and reversed with adequate hormone treatment, ${ }^{2-7}$ the role of thyroid hormone replacement therapy on the respiratory system in patients with nonthyroidal illness syndrome remains to be clarified. In a previous report on subjects on mechanical ventilation who were admitted to the ICU, we found that subjects affected by nonthyroidal illness syndrome had a higher mortality and a longer duration of mechanical ventilation and ICU length of stay than those with normal results of thyroid function tests. ${ }^{8}$ In that study, the low-triiodothyronine state was found to be an independent risk factor for prolonged mechanical ventilation. It is unclear, however, whether nonthyroidal illness syndrome is only a biochemical prognostic marker or it actually contributes to the development and progression of respiratory failure. The aim of this study was to evaluate the effect of thyroid hormone substitution treatment on respiratory muscle function in subjects on mechanical ventilation and with nonthyroidal illness syndrome.

\footnotetext{
A Gemelli 8, 00168 Rome, Italy. Dr Troiani is affiliated with Dipartimento di Scienze di Laboratorio e Infettivologiche; UOC di Chimica, Biochimica e Biologia Molecolare; Fondazione Policlinico Universitario Agostino Gemelli IRCCS, Roma; Istituto di Chimica, Biochimica e Biologia Molecolare; Università Cattolica del Sacro Cuore Largo A Gemelli 8, 00168 Rome, Italy. Drs Bianchi and Pontecorvi are affiliated with Dipartimento di Scienze Gastroenterologiche, Endocrino-Metaboliche e Nefro-Urologiche; UOC di Endocrinologia e Diabetologia; Fondazione Policlinico Universitario Agostino Gemelli IRCCS, Roma; Istituto di Endocrinologia e Diabetologia; Università Cattolica del Sacro Cuore, Largo A Gemelli 8, 00168 Rome, Italy.
}

The authors have disclosed no conflicts of interest.

Correspondence: Giuseppe Bello MD, Dipartimento di Scienze dell'Emergenza, Anestesiologiche e della Rianimazione, UOC di Anestesia, Rianimazione, Terapia Intensiva e Tossicologia Clinica, Istituto di Anestesia e Rianimazione, Fondazione Policlinico Universitario Agostino Gemelli IRCCS, Roma; Università Cattolica del Sacro Cuore; Largo A Gemelli 8, 00168 Rome, Italy. E-mail: gsppbll@gmail.com.

DOI: $10.4187 /$ respcare.06770

\section{QUICK LOOK}

\section{Current knowledge}

Several respiratory abnormalities, for example, diaphragmatic dysfunction, can be present in primary hypothyroidism and can be reversed with adequate hormone treatment.

\section{What this paper contributes to our knowledge}

Subjects on mechanical ventilation and with nonthyroidal illness syndrome and a failed spontaneous breathing trial did not show any changes in neuromechanical efficiency, calculated as the ratio between the drop in airway pressure during an expiratory occlusion and the corresponding peak of the electrical activity of the diaphragm. In subjects on mechanical ventilation and with nonthyroidal illness syndrome, thyroid hormone replacement therapy did not yield early benefits on diaphragmatic function, suggesting that alterations in serum hormone levels did not need to be corrected.

\section{Methods}

\section{Subject Selection}

This study was conducted in the 20-bed general ICU of the Fondazione Policlinico Universitario Agostino Gemelli IRCCS, Rome, Italy. The protocol was pre-approved by the ethics committee of Università Cattolica del Sacro Cuore (approval 28446/17), and written informed consent was obtained from all enrolled subjects or their next of kin. During the study, we enrolled 15 subjects who were on mechanical ventilation for at least $48 \mathrm{~h}$ and who had a diagnosis of nonthyroidal illness syndrome and experienced weaning failure after a spontaneous breathing trial (SBT).

Exclusion criteria were the following: age $<18$ years, pregnancy or estro-progestinic therapy, tracheostomy, neurologic or neuromuscular pathology and/or known phrenic nerve dysfunction, any contraindication to the insertion of a nasogastric tube (eg, recent upper-gastrointestinal surgery, esophageal varices), previously diagnosed intrinsic thyroid disease, known or suspected pituitary-hypothalamic disease, severe obesity (body mass index $>35 \mathrm{~kg} / \mathrm{m}^{2}$ ), ischemic cardiopathy, complex ventricular arrhythmias, serum cortisol $<80 \mathrm{ng} / \mathrm{mL}$ (to restrict endocrine disorders to the low-triiodothyronine state as far as possible), renal or hepatic failure (creatininemia $\geq 3.5 \mathrm{mg} / \mathrm{dL}$ or bilirubinemia $\geq 6.0 \mathrm{mg} / \mathrm{dL}$, respectively), transfusion of plasma within $48 \mathrm{~h}$ before thyroid hormone assessment, use of amiodarone in the previous 8 weeks use of iodine contrast agents in the previous 8 weeks hemodialysis, and expected poor 
outcomes. Patients with nonthyroidal illness syndrome were defined as those with low serum levels of free triiodothyronine, normal or low serum levels of free thyroxine, and normal or low serum levels of thyroid-stimulating hormone.

\section{Study Protocol}

In the subjects with a failed SBT, basal blood samples were immediately collected from an arterial line to determine thyroid hormone serum levels. All patients who showed a low-triiodothyronine condition received intravenous synthetic triiodothyronine (Thyrotardin, SanofiAventis Deutschland, Frankfurt am Main, Germany) and were enrolled in the study. Soon before starting hormone treatment (baseline) and after 3, 6, and $24 \mathrm{~h}$ from baseline, we recorded respiratory parameters. Throughout the study, enrolled subjects were on ventilation with pressure-support ventilation by using a Servo U ventilator equipped with the neurally-adjusted ventilatory assist (NAVA) software (Maquet, Solna, Sweden). We set the inspiratory pressure support to obtain a tidal volume of $6-8 \mathrm{~mL} / \mathrm{kg}$ of predicted body weight, an inspiratory flow trigger of $2-5$ $\mathrm{L} / \mathrm{min}$, checking for the absence of auto-trigger phenomena, and a cycling-off flow threshold of $30-50 \%$ of the peak inspiratory flow. PEEP and $\mathrm{F}_{\mathrm{IO}_{2}}$ were maintained at the values in use before subject enrollment. Ventilator settings were kept unchanged for the duration of the study unless clinically contraindicated. The endotracheal tube was suctioned before each study point.

Thyroid hormone replacement treatment consisted of an intravenous bolus of $0.4 \mu \mathrm{g} / \mathrm{kg}$ triiodothyronine, followed by continuous perfusion at $0.6 \mu \mathrm{g} / \mathrm{kg}$ per $24 \mathrm{~h}$, as previously described.9,10 Treatment was then stopped and resumed on the next day by the sublingual route, with a triiodothyronine dose assessed on the basis of new thyroid hormone tests to maintain hormone-circulating levels within normal limits. Electrocardiogram, invasive blood pressure, and peripheral $\mathrm{S}_{\mathrm{pO}_{2}}$ were monitored continuously throughout the entire thyroid hormone infusion period. A flowchart of the subject recruitment process is shown in Figure 1.

\section{Measurements}

NAVA is a form of partial ventilatory support wherein the machine adjusts ventilator assistance to the electrical activity of the diaphragm $\left(\mathrm{EA}_{\mathrm{di}}\right)$, which is the best available signal to estimate the respiratory drive, and to trigger on and cycle off the delivery of mechanical assistance and to regulate ventilation and intra-breath profile. ${ }^{11-13}$ If $\mathrm{EA}_{\mathrm{di}}$ is expressed in relation to airway pressure $\left(\mathrm{P}_{\mathrm{aw}}\right)$ during an inspiratory effort against an occluded respiratory circuit, the $\mathrm{P}_{\mathrm{aw}} / \mathrm{EA}_{\mathrm{di}}$ (ie, inspiratory pressure generation normalized to neural inspiratory effort) represents neuromechani-

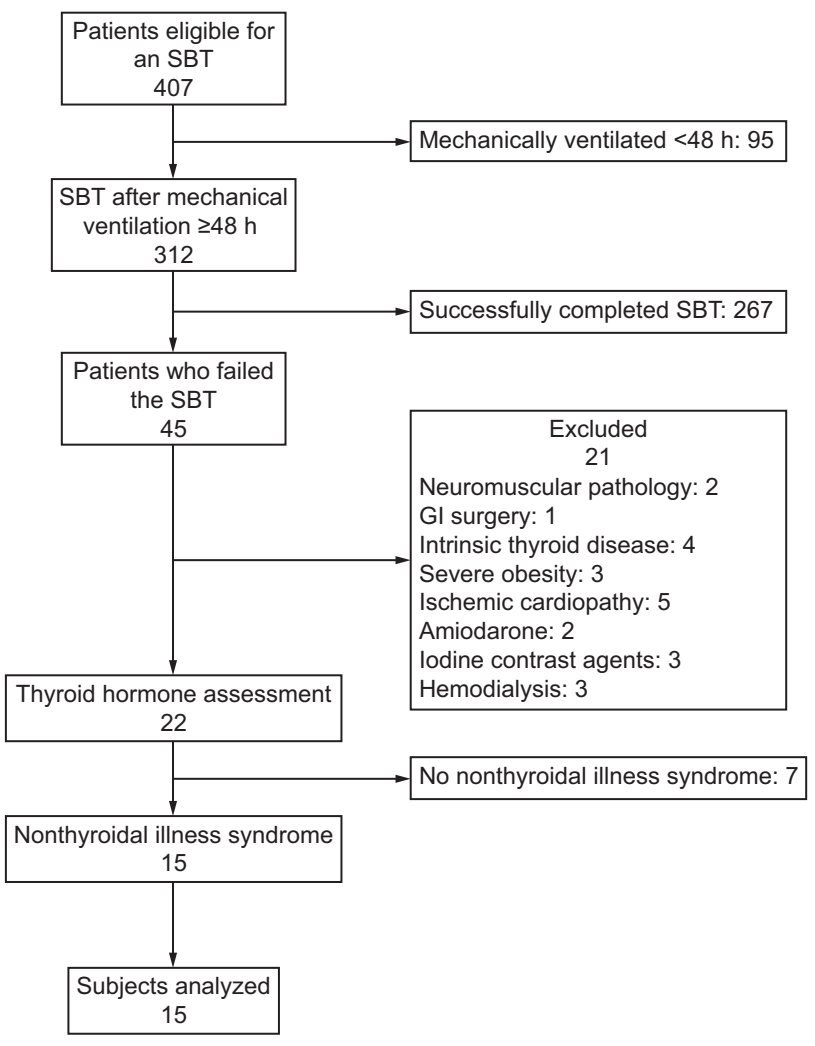

Fig. 1. Flow chart. SBT = spontaneous breathing trial, GI = gastrointestinal.

cal efficiency, which provides an estimate of efficiency of the diaphragmatic contraction. ${ }^{14-17}$

Our subjects were studied in the semi-recumbent position and on ventilation with a Servo U ventilator (Maquet) equipped with the NAVA software. At the beginning of the study, an $\mathrm{EA}_{\mathrm{di}}$ catheter was placed in each patient, with correct positioning of the catheter assessed through a specific function of the ventilator ( $\mathrm{EA}_{\mathrm{di}}$ catheter positioning). The $\mathrm{EA}_{\mathrm{di}}$ signal was processed by algorithms designed to reduce interferences related to variations in lung volume, chest-wall configuration, and changes in diaphragm position. ${ }^{18} \mathrm{EA}_{\mathrm{di}}$ was quantified every $16 \mathrm{~ms}$ by using the root mean square. ${ }^{19-20} \mathrm{P}_{\mathrm{aw}}$, flow, and $\mathrm{EA}_{\mathrm{di}}$ signals obtained from the RS232 port of the ventilator were stored in a personal computer at a sampling rate of $100 \mathrm{~Hz}$ (NAVA tracker software, Maquet). Subsequently, the NAVA tracker files were converted and analyzed by using the ICU Lab software package (Kleistek Engineering, Bari, Italy).

Respiratory parameters were calculated from the $\mathrm{EA}_{\mathrm{di}}$ signal according to Bellani et al. ${ }^{21}$ In summary, the pressure generated by respiratory muscles $\left(\mathrm{P}_{\text {mus }}\right)$ generally computed as the difference between esophageal pressure and the chest-wall elastic recoil curve) is tightly related to $\mathrm{EA}_{\mathrm{di}}$ by a proportionality coefficient, termed the $\mathrm{P}_{\mathrm{mus}} / \mathrm{EA}_{\mathrm{di}}$ index, which is stable within each patient under different 

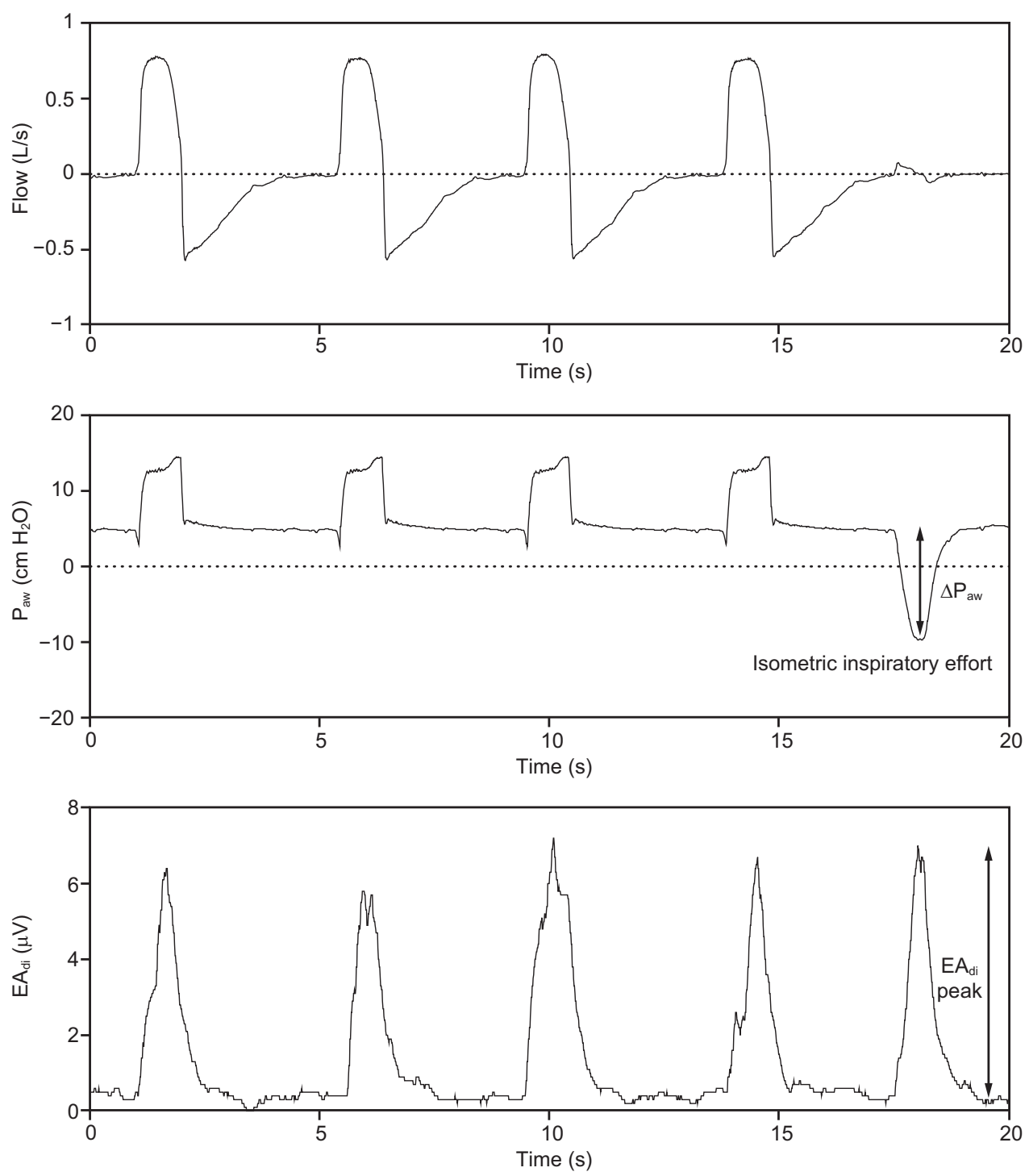

Fig. 2. Flow, airway pressure $\left(P_{a w}\right)$, and electrical activity of the diaphragm tracings during the maneuver were used to measure the neuromechanical efficiency. Neuromechanical efficiency was calculated as the ratio between the drop in $\mathrm{P}_{\text {aw }}$ during an expiratory occlusion and the corresponding electrical activity of the diaphragm $\left(E A_{d i}\right)$ peak.

conditions of ventilator assistance. The derivation of this index from the airway pressure signal during an expiratory occlusion represents a good surrogate of the $\mathrm{P}_{\text {mus }} / \mathrm{EA}_{\mathrm{di}}$ index measured during regular tidal ventilation, which thus allows a valuable estimate of inspiratory effort and prevents the need for esophageal pressure monitoring once the $\mathrm{EA}_{\mathrm{di}}$ measurement is available. ${ }^{21}$ Accordingly, because the fall in the airway pressure during a spontaneous inspiratory effort against the occluded airways (hence, in the absence of flow) equals the fall in esophageal pressure, which is a reasonable surrogate for transdiaphragmatic pressure $\left(\mathrm{P}_{\mathrm{di}}\right)$, we used neuromechanical efficiency as an index to convert the $\mathrm{EA}_{\mathrm{di}}$ signal into a $\mathrm{P}_{\mathrm{di}}$ signal.

The neuromechanical efficiency was calculated as the ratio between the peak negative value in airway pres- sure of a single inspiratory effort (recorded during a short end-expiratory occlusion) and the corresponding EA $_{\text {di }}$ peak ${ }^{14-17}$ (Fig. 2). The $\mathrm{P}_{\mathrm{di}}$ was calculated as: $\mathrm{P}_{\mathrm{di}}=\mathrm{EA}_{\mathrm{di}} \times$ neuromechanical efficiency. The pressure-time product of the $\mathrm{P}_{\mathrm{di}}$ per breath $\left(\mathrm{PTP}_{\mathrm{di}} /\right.$ breath) was calculated as the area under the $\mathrm{P}_{\mathrm{di}}$ signal, which was derived from the $\mathrm{EA}_{\mathrm{di}}$ curve during the assisted spontaneous breathing. The $\mathrm{PTP}_{\mathrm{di}}$ recorded over $1 \mathrm{~min}$ was referred to as $\mathrm{PTP}_{\mathrm{di}} / \mathrm{min}$.

\section{Primary and Secondary End Points}

The primary end point of this study was the subject's contractile diaphragmatic efficiency assessed by the neuromechanical efficiency over the first $24 \mathrm{~h}$ after start- 
ing triiodothyronine administration. Secondary end points were the subject's $\mathrm{PTP}_{\mathrm{di}}$ and swing of $\mathrm{EA}_{\mathrm{di}}$, which are surrogate estimates of work of breathing and inspiratory effort.

\section{Thyroid Laboratory Tests}

The normal ranges of serum hormone concentrations for our laboratory are as follows: free thyroxine, 8.5-15.5 $\mathrm{pg} / \mathrm{mL}$; free triiodothyronine, $2.3-4.2 \mathrm{pg} / \mathrm{mL}$; and thyroidstimulating hormone, $0.35-2.8 \mathrm{mIU} / \mathrm{mL}$. Our patients were considered eligible to participate in the study if they had serum free triiodothyronine concentrations $<2.0 \mathrm{pg} / \mathrm{mL}$. Serum thyroid hormones levels were determined by standard chemiluminescence immunoassay.

\section{Ventilator Weaning Procedure}

All the subjects had endotracheal tubes of at least 8-mm inner diameter. The process of weaning from the ventilator began with an assessment regarding readiness to wean, which was then followed by an SBT. The weaning criteria were the following: improvement or resolution of the underlying cause of acute respiratory failure, adequate mental status, absence of fever (body temperature $<38^{\circ} \mathrm{C}$ ), adequate cough, absence of excessive tracheobronchial secretion (frequency of endotracheal suctioning $<1$ every $3 \mathrm{~h}$ ), adequate oxygenation $\left(\mathrm{S}_{\mathrm{pO}_{2}}>90 \%\right.$ on $\mathrm{F}_{\mathrm{IO}_{2}} \leq 0.4$ or $\mathrm{P}_{\mathrm{aO}_{2}} / \mathrm{F}_{\mathrm{IO}_{2}} \geq 150 \mathrm{~mm} \mathrm{Hg}$, with a PEEP $\leq 5 \mathrm{~cm} \mathrm{H}_{2} \mathrm{O}$ ), hemodynamic stability (heart rate $\leq 140$ beats/min and systolic blood pressure of $90-160 \mathrm{~mm} \mathrm{Hg}$, with no need of vasopressors), hemoglobin $\geq 7 \mathrm{~g} / \mathrm{dL}$, adequate pulmonary function (absence of acidosis, maximum inspiratory pressure of $-20 \mathrm{~cm} \mathrm{H}_{2} \mathrm{O}$ or less and measured during a brief period of spontaneous breathing, frequency $\leq 35$ breaths/min, tidal volume $>5 \mathrm{~mL} / \mathrm{kg}$ predicted body weight, and rapid shallow breathing index $<105$ ). If the subjects did not meet these criteria when first tested, then they were evaluated daily until the criteria were fulfilled. When the above-mentioned criteria were fulfilled, the subjects underwent an SBT that lasted 30 min, which was performed with pressure-support ventilation of $7 \mathrm{~cm} \mathrm{H} \mathrm{H}_{2} \mathrm{O}$, no PEEP, and an $\mathrm{F}_{\mathrm{IO}_{2}}$ set at the same level as that used during mechanical ventilation.

SBT failure was defined as the presence and persistence of one of the following criteria: change in mental status (somnolence or agitation), diaphoresis, cyanosis, discomfort, increased accessory muscle activity, frequency $>35$ breaths/min, rapid shallow breathing index $>105, \mathrm{~S}_{\mathrm{pO}_{2}}<$ $90 \%$ at $\mathrm{F}_{\mathrm{IO}_{2}} \geq 0.4$ or $<80 \%$ in chronic respiratory failure, an increase in $\mathrm{P}_{\mathrm{aCO}_{2}}>10 \mathrm{~mm} \mathrm{Hg}, \mathrm{pH}<7.32$, hemodynamic instability (heart rate $>140$ beats/min or changed $>20 \%$, systolic blood pressure $>180$ or $<90 \mathrm{~mm} \mathrm{Hg}$ or changed $>20 \%$, or cardiac arrhythmias). If no signs of SBT failure appeared in $30 \mathrm{~min}$, the trial was considered successful and the subject was extubated. On the contrary, if signs of poor tolerance occurred at any time during the SBT, then mechanical ventilation was reinstituted and the subject was evaluated daily until the criteria were satisfied.

\section{Statistical Analysis}

The sample size of this physiologic study was not formally calculated, and we collected $>30$ normally distributed observations that were sufficient to perform parametric tests. Data distribution was assessed with the Kolmogorov-Smirnov test. Continuous variables with normal distributions were expressed as mean $\pm \mathrm{SD}$, whereas those with non-normal distributions were expressed as median and interquartile ranges. Categorical variables were presented as group proportions. The analysis of variance for repeated measures was performed to detect significant differences among the different experimental conditions. $P$ values $<.05$ were considered statistically significant. MedCalc Statistical Software version 14.12.0 (MedCalc Software bvba, Ostend, Belgium) was used for all statistical analyses.

\section{Results}

A flow diagram that depicts subject identification and enrollment is shown in Figure 1. During the study period, 515 patients were admitted to our general ICU. Among these patients, $14 \%$ of those (45/312) who were receiving mechanical ventilation for at least $48 \mathrm{~h}$ and met the weaning criteria had a failed SBT. Finally, $68 \%$ of the patients $(15 / 22)$ who underwent thyroid function testing showed a low-triiodothyronine state and were included in the study. The main clinical characteristics of the subjects are shown in Table 1.22

Synthetic triiodothyronine infusion was well tolerated, and no adverse effects were reported in terms of blood pressure, heart rate changes (Table 2), or appearance of ischemic episodes or significant arrhythmias. No changes were observed in arterial blood gases throughout the protocol (Table 2). No subjects received sedative drugs after enrollment, whereas some subjects were given remifentanil at doses of $<0.05 \mu \mathrm{g} / \mathrm{kg} / \mathrm{min}$, which does not affect the respiratory drive $\left(\mathrm{EA}_{\mathrm{di}}\right)$ nor breathing frequency. ${ }^{23}$ There was no intrinsic PEEP in any of the subjects. No subject required a change in ventilator settings during the study (mean \pm SD PEEP, $4.7 \pm 0.46 \mathrm{~cm} \mathrm{H}_{2} \mathrm{O}$; pressure support $9.6 \pm 0.83 \mathrm{~cm} \mathrm{H}_{2} \mathrm{O}$ ). After starting triiodothyronine replacement treatment, free-triiodothyronine concentrations increased in all the subjects (mean $\pm \mathrm{SD}$ increase on the day after study completion, $0.84 \pm 0.34 \mathrm{pg} / \mathrm{mL}$ ). Trends of neuromechanical efficiency, swing of $\mathrm{EA}_{\mathrm{di}}$, and $\mathrm{PTP}_{\mathrm{di}}$ values are depicted in Figure 3. One-way analysis of variance for repeated measures did not show any significant differences 


\section{Thyroid Hormone Treatment and Respiratory Muscle Function}

within study points for all the study parameters (Fig. 3, Table 3).

\section{Discussion}

This study demonstrated that, in subjects on ventilation who were admitted to the ICU with nonthyroidal illness syndrome, thyroid hormone replacement therapy did not yield early benefit on respiratory muscle function when assessed by neuromechanical efficiency. More specifically, 1-way analysis of variance for repeated measures did not

Table 1. Characteristics of the Study Population and Main Outcomes

\begin{tabular}{lc}
\hline \multicolumn{1}{c}{ Variable } & Result \\
\hline Age, median (IQR) y & $74(62.5-76.5)$ \\
Males, $n(\%)$ & $10(66.6)$ \\
Underlying disease, $n(\%)$ & \\
$\quad$ Pneumonia & $5(33.3)$ \\
$\quad$ Multiple trauma & $4(26.6)$ \\
$\quad$ Postoperative bleeding & $2(13.3)$ \\
$\quad$ Head trauma & $1(6.6)$ \\
Intestinal obstruction & $1(6.6)$ \\
$\quad$ Hypersensitivity pneumonitis & $1(6.6)$ \\
Gastrointestinal bleeding & $1(6.6)$ \\
SAPS II, median (IQR) & $49(41.5-66.5)$ \\
Duration of ventilation, median (IQR) d & $7(5.5-8,5)$ \\
ICU LOS, median (IQR) d & $7(5.5-8,5)$ \\
ICU deaths, $n$ (\%) & $4(26.6)$ \\
Thyroid hormones, median (IQR)* & \\
Free triiodothyronine, pg/mL & $1.6(1.32-1.7)$ \\
Free thyroxine, pg/mL & $8.3(7.75-9.35)$ \\
Thyroid-stimulating hormone, mIU/mL & $0.68(0.47-2.86)$ \\
\hline$N=15$. & \\
IQR = interquartile range (25th-75th percentile) & \\
SAPS = Simplified Acute Physiology Score [22] & \\
\hline & \\
\hline & \\
\hline & \\
\hline &
\end{tabular}

show any significant differences in neuromechanical efficiency values at 3,6 , and $24 \mathrm{~h}$ after starting thyroid hormone administration. Similarly, also, the $\mathrm{PTP}_{\mathrm{di}}$ and the swing of $\mathrm{EA}_{\mathrm{di}}$, which reflect the work of breathing and the inspiratory effort of the patient, respectively, did not show any significant changes during hormone administration. Neuromechanical efficiency (otherwise referred to as the $\mathrm{P}_{\text {mus }} / \mathrm{EA}_{\mathrm{di}}$ index $\left.{ }^{21}\right)$ is an estimate of diaphragmatic efficiency in patients on ventilation ${ }^{14-17}$ and is thought to indicate the amount of pressure that the respiratory muscles are developing for each microvolt of electrical activity. The derivation of the work of breathing from the $\mathrm{EA}_{\mathrm{di}}$ signal is of considerable importance in the assessment of respiratory failure in the clinical setting.

Today, it still remains unclear whether patients affected by nonthyroidal illness syndrome are biochemically hypothyroid, and, accordingly, there is no consensus about correcting serum thyroid hormone concentrations in these patients. Recently, much effort has been spent in attempting to clarify whether patients with nonthyroidal illness syndrome are to be treated. In this context, establishing an appropriate clinical end point has been one of the greatest difficulties for investigators. The aim of hormone treatment should not pretend to cure patients who are critically ill and with nonthyroidal illness syndrome but to contribute somehow to their recovery from critical illness. Theoretically, if patients with nonthyroidal illness syndrome were actually hypothyroid, then the normalization of their circulating thyroid hormone levels might reverse at least some of the typical abnormalities that may be attributable to hypothyroidism and that have no other evident explanation, including mental obtundation; dry skin; hypothermia; bradycardia; hypotension; sluggish tendon reflexes; constipation; pleural, pericardial, or peritoneal effusions; weight gain; hair loss; anemia and increased serum levels of triglycerides, creatinine phosphokinase, lactate dehydrogenase, or glutamic-oxaloacetic transaminase. Unfortunately, each of these disorders may result from a wide

Table 2. Arterial Blood Gas and Hemodynamic Variables During the Four Study Points

\begin{tabular}{lcccc}
\hline \hline \multicolumn{1}{c}{ Parameter* } & Baseline & $3 \mathrm{~h}$ & $6 \mathrm{~h}$ & $24 \mathrm{~h}$ \\
\hline $\mathrm{pH}$ & $7.44 \pm 0.04$ & $7.45 \pm 0.03$ & $7.47 \pm 0.04$ & $7.46 \pm 0.05$ \\
$\mathrm{P}_{\mathrm{aCO}_{2}, \mathrm{~mm} \mathrm{Hg}}$ & $46.5 \pm 12.5$ & $43.5 \pm 10.9$ & $42.5 \pm 10.1$ & $43.7 \pm 12.1$ \\
$\mathrm{P}_{\mathrm{aO}} / \mathrm{F}_{\mathrm{IO}_{2}}, \mathrm{~mm} \mathrm{Hg}$ & $291 \pm 86.4$ & $302.7 \pm 114.3$ & $324.2 \pm 104.7$ & $334.7 \pm 100.3$ \\
$\mathrm{Bicarbonate} \mathrm{mmol} / \mathrm{L}$ & $31.4 \pm 5.6$ & $30.7 \pm 6.2$ & $31 \pm 6$ & $31.8 \pm 7.7$ \\
$\mathrm{Heart} \mathrm{rate}, \mathrm{beats} / \mathrm{min}$ & $86.2 \pm 16.8$ & $84.2 \pm 17.9$ & $85.4 \pm 13.6$ & $86.3 \pm 13.8$ \\
$\mathrm{SBP}, \mathrm{mm} \mathrm{Hg}$ & $143 \pm 15.8$ & $135.2 \pm 21.2$ & $139 \pm 18.1$ & $62.9 \pm 6.8$ \\
$\mathrm{DBP}, \mathrm{mm} \mathrm{Hg}$ & $68.4 \pm 9.1$ & $62.5 \pm 9$ & $63.3 \pm 17.5$ &
\end{tabular}

Data are expressed as mean $\pm \mathrm{SD}$.

* For each parameter, 1-way analysis of variance for repeated measures showed no significant differences within study points.

$\mathrm{SBP}=$ systolic blood pressure

$\mathrm{DBP}=$ diastolic blood pressure 

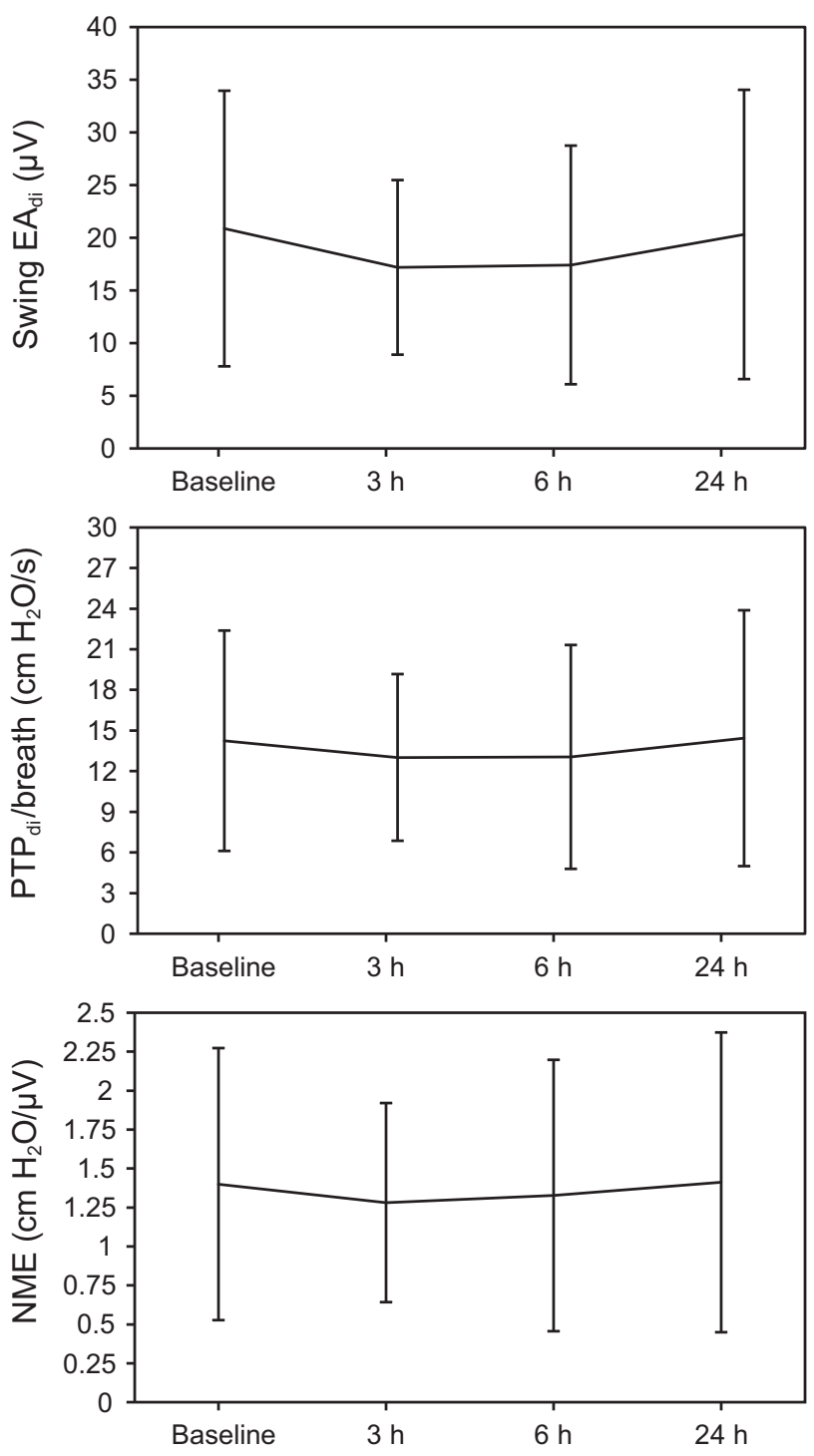

Fig. 3. Main respiratory parameters during the 4 study points. For each parameter, 1-way analysis of variance for repeated measures showed no significant differences within study points. $\mathrm{EA}_{\mathrm{di}}=$ electrical activity of the diaphragm; PTP $_{\mathrm{di}}=$ pressure-time product of the diaphragm (derived from the $\mathrm{EA}_{\mathrm{di}}$ signal); $\mathrm{NME}=$ neuromechanical efficiency.

variety of factors commonly present in patients admitted to the ICU. Hence, it would be difficult to show any correlation between hormone treatment and correction of these disorders. On the contrary, clinical end points, such as physiologic functions, seem to be more suitable for evaluating the actual role of thyroid hormone supplementation in patients with nonthyroidal illness syndrome.

In this respect, some investigators explored the effect of triiodothyronine treatment on cardiac function in subjects who were critically ill and with heart disorders, but their results were inconsistent.9,24-27 Also, respiratory function was deemed to be potentially affected by a low-triiodo- thyronine state. In a retrospective analysis of subjects with nonthyroidal illness syndrome admitted to our ICU, we previously reported that the subjects with a low-triiodothyronine state show a longer duration of mechanical ventilation compared with those with normal serum hormone levels. ${ }^{8}$ That study, however, did not clarify whether nonthyroidal illness syndrome simply indicates a severe clinical condition or is, at least in part, responsible for respiratory impairment. Another study, on elderly subjects ( $>65 \mathrm{y}$ ) admitted to the ICU for acute respiratory failure due to exacerbation of COPD, showed that subjects with nonthyroidal illness syndrome had a higher failure rate of noninvasive ventilation than subjects without nonthyroidal illness syndrome. ${ }^{28}$ To the best of our knowledge, ours was the first study to seek possible effects of thyroid hormone treatment on respiratory function in critically ill subjects on ventilation and with nonthyroidal illness syndrome in the context of personalized medicine.

The present study was conceived to last only $24 \mathrm{~h}$ to minimize possible changes in the patient's clinical features and to avoid potential interferences with the study end points. However, although no benefit in respiratory muscle function was found during the first $24 \mathrm{~h}$ of hormone administration, improvements cannot be completely ruled out because these may have occurred belatedly, after completion of the study. Also, we performed laboratory testing from the first hours after enrollment because protein synthesis induced by triiodothyronine begins within the first hour after hormone administration and reaches its peak a few hours later. ${ }^{29}$ Also, subjects were enrolled in this study only when they experienced an SBT failure. In this way, the subjects had similar clinical features because they all met the criteria for beginning weaning procedures. It is possible that our subjects might not have been sick enough to benefit from thyroid hormone supplementation. However, respiratory parameters throughout the study registration period followed a similar trend in the subjects, with either slightly or severely low concentrations of serum thyroid hormone and, therefore, with different levels of nonthyroidal illness syndrome severity.

Even though our study did not find statistically significant results, we believe that our study provided a valuable message regarding the usefulness of restoring thyroid hormone concentrations in patients with nonthyroidal illness syndrome and who are critically ill. In fact, correcting low triiodothyronine is controversial, and with no definitive results found in cardiac subjects ${ }^{9,24-27}$ or benefits in respiratory muscle function in our subjects, we can argue that giving thyroid hormone to patients affected by nonthyroidal illness syndrome may not be justified. Furthermore, regarding the significance of nonthyroidal illness syndrome in patients admitted to the ICU and on mechanical ventilation, ${ }^{8}$ abnormalities in serum thyroid hormone levels in these patients would seem to be only a biochemical marker 
Table 3. Respiratory Parameters During the Four Study Points

\begin{tabular}{|c|c|c|c|c|}
\hline Parameter* & Baseline & $3 \mathrm{~h}$ & $6 \mathrm{~h}$ & $24 \mathrm{~h}$ \\
\hline $\mathrm{V}_{\mathrm{T}} / \mathrm{PBW}, \mathrm{mL} / \mathrm{kg}$ & $7.1 \pm 0.7$ & $7.2 \pm 0.6$ & $7.1 \pm 0.6$ & $7.2 \pm 0.5$ \\
\hline $\mathrm{NME}, \mathrm{cm} \mathrm{H} \mathrm{H}_{2} \mathrm{O} / \mu \mathrm{V}$ & $1.40 \pm 0.87$ & $1.28 \pm 0.64$ & $1.33 \pm 0.87$ & $1.41 \pm 0.96$ \\
\hline Swing $\mathrm{EA}_{\mathrm{di}}, \mu \mathrm{V}$ & $20.9 \pm 13.1$ & $17.2 \pm 8.3$ & $17.4 \pm 11.3$ & $20.3 \pm 13.7$ \\
\hline Peak $\mathrm{P}_{\mathrm{aw}}, \mathrm{cm} \mathrm{H}_{2} \mathrm{O}$ & $7.4 \pm 2.9$ & $7.4 \pm 2.9$ & $7.5 \pm 2.9$ & $7.5 \pm 3.4$ \\
\hline Peak flow, L/s & $0.83 \pm 0.13$ & $0.83 \pm 0.15$ & $0.84 \pm 0.19$ & $0.85 \pm 0.15$ \\
\hline $\mathrm{PTP}_{\mathrm{di}} /$ breath, $\mathrm{cm} \mathrm{H}_{2} \mathrm{O} \times \mathrm{s}$ & $14.3 \pm 8.1$ & $13 \pm 6.2$ & $13.1 \pm 8.3$ & $14.4 \pm 9.4$ \\
\hline $\mathrm{PTP}_{\mathrm{di}} / \mathrm{min}, \mathrm{cm} \mathrm{H}_{2} \mathrm{O} \times \mathrm{s} / \mathrm{min}$ & $238.1 \pm 124$ & $242.5 \pm 140.3$ & $247.5 \pm 161.7$ & $281.2 \pm 201.2$ \\
\hline \multicolumn{5}{|c|}{$\begin{array}{l}\text { Data are expressed as mean } \pm \text { SD. } \\
* \text { For each parameter, 1-way analysis of variance for repeated measures showed no significant differences within study points. } \\
V_{T}=\text { tidal volume } \\
\text { PBW = predicted body weight } \\
\text { NME }=\text { neuromechanical efficiency } \\
\mathrm{EA}_{\mathrm{di}}=\text { electrical activity of the diaphragm } \\
\mathrm{P}_{\mathrm{aw}}=\text { airway pressure } \\
\mathrm{PTP}_{\mathrm{di}}=\text { pressure-time product of the diaphragm (derived from the } \mathrm{EA}_{\mathrm{di}} \text { signal) }\end{array}$} \\
\hline
\end{tabular}

of the severity of illness rather than a condition that contributes to the development of respiratory failure.

This study had some limitations. First, the use of serum free triiodothyronine, free thyroxine, and thyroid-stimulating hormone levels as a screening method may be insufficient to accurately define the nature of the various disorders in thyroid function tests. In the critical care setting, patients with hyperthyroid may have paradoxically low levels of thyroid hormones until their recovery from the critical illness, ${ }^{30}$ and patients with primary hypothyroidism may fail to manifest increased thyroid-stimulating hormone. ${ }^{31}$ In addition, the presence of a low serum thyroid stimulating hormone level may be associated with a nonthyroidal illness syndrome per se but also with a pituitary or hypothalamic disease. However, given the very low incidence of these particular conditions, we believe that the screening method used in this study did not cause significant flaws. Second, this physiologic study was conducted in 15 subjects in the ICU, which means that caution must be used in extrapolating our findings to all patients who are critically ill. Third, the lack of a control group did not allow us to describe the trend of respiratory parameters in the absence of thyroid hormone treatment, although no significant changes were found in these parameters, not even after thyroid hormone supplementation. Fourth, we measured PTP $_{\mathrm{di}}$ from the $\mathrm{EA}_{\mathrm{di}}$ signal rather than the $\mathrm{P}_{\mathrm{di}}$ curves obtained by the use of an esophageal balloon.

However, it is now widely accepted that the $\mathrm{EA}_{\mathrm{di}}$ signal is a reliable tool for deriving $\mathrm{P}_{\mathrm{di}}$ values and estimating the patient's work of breathing without the need for esophageal pressure monitoring. ${ }^{14,21,32}$ Also, even though the neuromechanical efficiency derived from the airway pressure during an end-expiratory occlusion is a good estimate of the neuromechanical efficiency measured during regular tidal ventilation, some investigators suggest calculating the neuromechanical efficiency measured during ventila- tion by dividing the neuromechanical efficiency measured during an occlusion maneuver by a specific correction factor. $^{21}$ In the present study, we did not apply any correction factor in measuring the study parameters, despite a possible overestimation of the "dynamic" neuromechanical efficiency because we were only interested in the trend of the variables.

\section{Conclusions}

Thyroid hormone replacement treatment did not yield any benefit on respiratory muscle function assessed by neuromechanical efficiency in subjects with nonthyroidal illness syndrome and who were critically ill and admitted to the ICU. This work reinforced the view that nonthyroidal illness syndrome is an adaptive clinical condition that should not be corrected.

\section{REFERENCES}

1. Bello G, Ceaichisciuc I, Silva S, Antonelli M. The role of thyroid dysfunction in the critically ill: a review of the literature. Minerva Anestesiol 2010;76(11):919-928.

2. Ambrosino N, Pacini F, Paggiaro PL, Martino E, Contini V, Turini $\mathrm{L}$, et al. Impaired ventilatory drive in short-term primary hypothyroidism and its reversal by L-triiodothyronine. J Endocrinol Invest 1985;8(6):533-536.

3. Ladenson PW, Goldenheim PD, Ridgway EC. Prediction and reversal of blunted ventilatory responsiveness in patients with hypothyroidism. Am J Med 1988;84(5):877-883.

4. Brüssel T, Matthay MA, Chernow B. Pulmonary manifestations of endocrine and metabolic disorders. Clin Chest Med 1989;10(4):645653.

5. Martinez FJ, Bermudez-Gomez M, Celli BR. Hypothyroidism: a reversible cause of diaphragmatic dysfunction. Chest 1989;96(5): 1059-1063.

6. Gorini M, Spinelli A, Cangioli C, Gigliotti F, Duranti R, Arcangeli $\mathrm{P}$, Scano G. Control of breathing in patients with short-term primary hypothyroidism. Lung 1989(1):167:43-53. 


\section{Thyroid Hormone Treatment and Respiratory Muscle Function}

7. Siafakas NM, Salesiotou V, Filaditaki V, Tzanakis N, Thalassinos N, Bouros D. Respiratory muscle strength in hypothyroidism. Chest 1992;102(1):189-194

8. Bello G, Pennisi MA, Montini L, Silva S, Maviglia R, Cavallaro F, et al. Nonthyroidal illness syndrome and prolonged mechanical ventilation in patients admitted to the ICU. Chest 2009;135(6):14481454.

9. Slutsky AS. Mechanical ventilation. American College of Chest Physicians' Consensus Conference. Chest 1993;104(6):1833-1859.

10. Sinderby C, Navalesi P, Beck J, Skrobik Y, Comtois N, Friberg S, et al. Neural control of mechanical ventilation in respiratory failure. Nat Med 1999;5(12):1433-1436.

11. Navalesi P, Costa R. New modes of mechanical ventilation: proportional assist ventilation, neurally adjusted ventilatory assist, and fractal ventilation. Curr Opin Crit Care 2003;9(1):51-58.

12. Beck J, Gottfried SB, Navalesi P, Skrobik Y, Comtois N, Rossini M, Sinderby C. Electrical activity of the diaphragm during pressure support ventilation in acute respiratory failure. Am J Respir Crit Care Med 2001;164(3):419-424.

13. Liu L, Liu H, Yang Y, Huang Y, Liu S, Beck J, et al. Neuroventilatory efficiency and extubation readiness in critically ill patients. Crit Care 2012;16(4):R143.

14. Doorduin J, van Hees HW, van der Hoeven JG, Heunks LM. Monitoring of the respiratory muscles in the critically ill. Am J Respir Crit Care Med 2013;187(1):20-27.

15. Laghi F, Shaikh HS, Morales D, Sinderby C, Jubran A, Tobin MJ. Diaphragmatic neuromechanical coupling and mechanisms of hypercapnia during inspiratory loading. Respir Physiol Neurobiol 2014; 198:32-41.

16. Mullis-Jansson SL, Argenziano M, Corwin S, Homma S, Weinberg $\mathrm{AD}$, Williams $\mathrm{M}$, et al. A randomized double-blind study of the effect of triiodothyronine on cardiac function and morbidity after coronary bypass surgery. J Thorac Cardiovasc Surg 1999;117(6): 1128-1134.

17. Peeters RP, van der Geyten S, Wouters PJ, Darras VM, van Toor H, Kaptein E, et al. Tissue thyroid hormone levels in critical illness. J Clin Endocrinol Metab 2005;90(12):6498-6507.

18. Sinderby CA, Beck JC, Lindström LH, Grassino AE. Enhancement of signal quality in esophageal recordings of diaphragm EMG. J Appl Physiol 1997;82(4):1370-1377.

19. Hill LL, Pearl RG. Flow triggering, pressure triggering, and autotriggering during mechanical ventilation. Crit Care Med 2000;28(2): 579-581.

20. Sinderby C, Beck J, Spahija J, de Marchie M, Lacroix J, Navalesi P, Slutsky AS. Inspiratory muscle unloading by NAVA during maxi- mal inspiratory efforts in healthy subjects. Chest 2007;131(3):711 717.

21. Bellani G, Mauri T, Coppadoro A, Grasselli G, Patroniti N, Spadaro $\mathrm{S}$, et al. Estimation of patient's inspiratory effort from the electrical activity of the diaphragm. Crit Care Med 2013;41(6):1483-1491.

22. Le Gall JR, Lemeshow S, Saulnier F. A new Simplified Acute Physiology Score (SAPS II) based on a European/North American multicenter study. JAMA 1993;270(24):2957-2963.

23. Costa R, Navalesi P, Cammarota G, Longhini F, Spinazzola G, Cipriani $\mathrm{F}$, et al. Remifentanil effects on respiratory drive and timing during pressure support ventilation and neurally adjusted ventilatory assist. Respir Physiol Neurobiol 2017;244:10-16.

24. Klemperer JD, Klein I, Gomez M, Helm RE, Ojamaa K, Thomas SJ, et al. Thyroid hormone treatment after coronary-artery bypass surgery. N Engl J Med 1995;333(23):1522-1527.

25. Bennett-Guerrero E, Jimenez JL, White WD, D'Amico EB, Baldwin BI, Schwinn DA. Cardiovascular effects of intravenous triiodothyronine in patients undergoing coronary artery bypass graft surgery. A randomized, double-blind, placebo- controlled trial. Duke T3 study group. JAMA 1996;275(9):687-692.

26. Hamilton MA, Stevenson LW, Fonarow GC, Steimle A, Goldhaber JI, Child JS, et al. Safety and hemodynamic effects of intravenous triiodothyronine in advanced congestive heart failure. Am J Cardiol 1998;81(4):443-447.

27. Pingitore A, Galli E, Barison A, Iervasi A, Scarlattini M, Nucci D, et al. Acute effects of triiodothyronine (T3) replacement therapy in patients with chronic heart failure and low-T3 syndrome: a randomized, placebo-controlled study. J Clin Endocrinol Metab 2008;93(4): 1351-1358.

28. Ergan B, Ergün R, Aydin K, Ergün D. Nonthyroidal illness syndrome in severe chronic obstructive pulmonary disease exacerbations in the elderly. Turk J Geriatr 2016;19(2):67-73. Available at http://geriatri.dergisi.org/uploads/pdf/pdf_TJG_928.pdf

29. Powner DJ, Hendrich A, Lagler RG, Ng RH, Madden RL. Hormonal changes in brain dead patients. Crit Care Med 1990;18(7):702-708.

30. Engler D, Donaldson EB, Stockigt JR, Taft P. Hyperthyroidism without triiodothyronine excess: an effect of severe nonthyroidal illness. J Clin Endocrinol Metab 1978;46(1):77-82.

31. Hooper MJ. Letter: diminished T.S.H. secretion during acute nonthyroidal illness in untreated primary hypothyroidism. Lancet 1976; I(7949):48-49.

32. Di Mussi R, Spadaro S, Mirabella L, Volta CA, Serio G, Staffieri F, et al. Impact of prolonged assisted ventilation on diaphragmatic efficiency: NAVA versus PSV. Crit Care 2016;5:20:1.

This article is approved for Continuing Respiratory Care Education credit. For information and to obtain your CRCE

(free to AARC members) visit

www.rcjournal.com

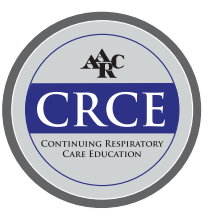

